\title{
APUNTES PARA UNA TEORÍA POÉTICA DE ALFONSO REYES EN EL CONTEXTO DE SUS CONTEMPORÁNEOS \\ José Barba Martín*
}

RESUMEN: El autor intenta deducir una teoría poética del escritor mexicano partiendo de su obra, que divide en tres partes; enseguida, tras un interludio - "la noche obscura del poeta"- trata la función del recuerdo como estímulo literario. Y termina con un apunte hacia el popularismo artístico de Alfonso Reyes.

\section{yos}

ABSTRACT: The author attempts to formulate a poetic theory of this Mexican writer based on his works, which is divided in three parts; after an interlude - "the poet's darkest night"- he studies how remembrance works as a literary stimulus and concludes commenting on Alfonso Reyes' artistic popularism.

PALABRAS CLAVE: Alfonso Reyes, poética, poesía, recuerdo, popularismo, tradición. KEYWORDS: Alfonso Reyes, poetics, poetry, remembrance, popularism, tradition.

RECEPCIÓN: 14 de noviembre de 2008.

APROBACIÓN: 29 de enero de 2009.

* Departamento Académico de Estudios Generales, ITAM. 
CITAM Derechos Reservados.

La reproducción total o parcial de este artículo se podrá hacer si el ITAM otorga la autorización previamente por escrito. 


\section{APUNTES PARA UNA TEORÍA POÉTICA DE ALFONSO REYES EN EL CONTEXTO DE SUS CONTEMPORÁNEOS}

Para Jeannine

A la poesía de un gran poeta corresponde siempre una poética más o menos organizada y formulada, un punto de vista general sobre la obra ya hecha o por hacer. Jorge Guillén, Lenguaje y poesía ${ }^{1}$

\section{Introducción}

La obra de Alfonso Reyes me fue una vez "asunto de gustoso estudio", frase que él mismo escribió en un libro suyo dedicado a la experiencia estética. Meminisse juvat; pensé, pues, que sería bueno aprovechar ciertas notas mías para compartir lo que algún tiempo gocé en lecturas solitarias, íntimas. Me es claro que la educación de la sensibilidad, como su expresión artística, responde a un lento proceso de formación cuasi-coralina. De igual manera, las muchas anotaciones marginales, cotejos y revisiones, hechos en un principio solamente con fines personales, van organizándose luego como materia crítica o tema de meditación y comunicación literarias.

$$
* * *
$$

La poesía de Alfonso Reyes, que podría considerarse como manifestación de una teoría poética abierta y claramente formulada, no aparece en su creación sino hasta 1925, veinte años después de la fecha de su

${ }^{1}$ Jorge Guillén, Language and Poetry, 1961, Cambridge, Mass., Harvard University Press, traducción al inglés de Ruth Whittredge, p. 108. 
JOSÉ BARBA MARTÍN

primer poema conocido. Antes de acercarme al vislumbre de su poética y a la verificación de su cumplimiento en la producción lírica de los años correspondientes, adelanto una nota que enmarca al hombre y su obra, y sondeo en sus primeros versos aquellas señales que preanuncian sus convicciones poéticas.

Alfonso Reyes nace un año después de la publicación de Azul (1888) y su primer poema conocido, "Huellas", no recogido en libro sino hasta 1922, lleva la fecha de 1906, justamente un año posterior a la aparición de Cantos de vida y esperanza, que marca, según el consenso general de críticos e historiadores, la línea divisoria entre las dos grandes etapas del modernismo hispanoamericano: la del refinado culto preferente de la forma y la de una interiorización de ahondamiento reflexivo en temas individuales, más espirituales, del poeta, sin abandono de la preocupación formal. Así, aunque no perteneció a la escuela modernista ni por generación ni por estética, llega Alfonso Reyes a la poesía bajo un signo favorable al equilibrio entre sentimiento y expresión, que ha de ser una característica definitiva en la unidad de su obra.

Afincado en la tradición grecolatina primero, y habituado a la asidua familiaridad con nuestros clásicos de los Siglos de Oro, sobre todo en poesía, con el Góngora de las "letrillas" y con Lope de Vega, es también, como Rubén Darío, "muy antiguo y muy moderno", y su cosmopolitismo sabe convivir con la poesía tangente al desarrollo de su propia vida creadora. Ahora bien, siendo fundamentalmente un humanista clásico, en esencia permanece fiel al espíritu e ideal poéticos que él se propuso conscientemente desde su juventud. En la quinta serie de sus Simpatías $y$ diferencias, diría más tarde (1926): "soy fiel a un ideal estético y ético a la vez, hecho de bien y belleza". ${ }^{2}$ Constancia poética, título que años después escogió para la colección completa de sus poemas, alude, a mi parecer, no sólo a la continuidad de su esfuerzo creador sino también a la fidelidad a su credo poético. Este sentido de lealtad a la intuición original de su poesía lo proyecta Reyes de sí mismo, indirectamente, queriendo definir a su amigo Enrique González Martínez, al prologar, en 1911, su libro Los senderos ocultos: "Su poesía -escribe Reyes- es como su vida: hay algo en ella que yo llamaría 'cartesianismo poético', una constante referencia a las primeras evidencias del espíritu.”

${ }^{2}$ Obras completas de Alfonso Reyes, 1956, México, FCE, vol. IV, p. 451. 
Así, una cibernética interior lo condujo siempre. Lo mismo que escribió en el poema titulado "El fraude" en relación con el amor -y amor fue para Reyes la literatura-, podría haberlo dicho en relación con la poesía: "nunca me engañó la brújula / que en el corazón traía".

\section{Poética y poesía}

La primera etapa (de 1906 a 1913)

Aunque, como indiqué antes, Alfonso Reyes no perteneció a la escuela modernista ni por estética ni por generación, sus primeros poemas manifiestan influencias que, en parte, como el modernismo, había recibido del parnasianismo y del simbolismo ${ }^{4}$ y coincide, en el fondo, con la actitud del modernismo por lo que toca a la estimación y al culto del verso. ${ }^{5}$ Mas, si el mundo clásico, materia predominante en Huellas (1922), el primer libro de poemas de Reyes, parece a primera vista corresponder directamente a esa misma faceta del modernismo, aunque el léxico y la onomástica suenen parecidas; aunque mencione a las mismas deidades, héroes y heroínas paganos y a personajes literarios de la antigüedad, su intención es distinta. Como dice en "A un poeta bucólico" (él mismo): [abreva] "el labio con gustoso paladeo / en vino añejo de tus hidrias nuevas". ${ }^{6}$

Ya observaron algunos críticos que la preferencia de la poesía modernista por el mundo clásico no es producto de un conocimiento directo de la antigüedad grecolatina, sino a través de Francia. A la confesión de Rubén Darío, por ejemplo: "Amo más que la Grecia de los griegos la Grecia de Francia”, E. Díez-Echarri y J. M. Roca-Franquesa comentan, con cierta desaprensión: "No es que la amase más; es que no conocía otra". ${ }^{7}$ Arturo Marasso, por su parte, en Rubén Darío y su creación

${ }^{3}$ Op. cit., vol. X, p. 465.

${ }^{4}$ E. Díez-Echarri-J. M. Roca Franquesa, Historia general de la literatura española e hispanoamericana, 1968, Madrid, Aguilar.

${ }^{5}$ Tomás Navarro Tomás; "Reyes en sus versos", en Presencia de Alfonso Reyes (Homenaje), 1969, México, FCE, p. 99.

${ }^{6}$ Obras completas de..., op. cit., vol. X, p. 27.

${ }^{7}$ Ibidem. 
poética, piensa que tuvo influencia determinante en Darío la lectura de Mythologie dans l'art ancien et modern, de René Ménard (París, 1878). Pero el caso de Alfonso Reyes es diferente, aun antes del mayor desarrollo de su interés en estudios posteriores sobre Grecia y Roma. La temática clásica de su poesía no es puramente decorativa sino, desde el principio, espiritual, poéticamente programática. Y si en este trabajo se presta particular atención a los poemas de inspiración clásica en la primera producción lírica de Alfonso Reyes, es porque en ellos se logran los primeros atisbos de su poética.

Como se observó desde hace mucho tiempo, en "De mi prisma" (1906), el primero de sus poemas, fechado cuando el poeta cuenta sólo diecisiete años, se encuentran ya tres de las características que acompañarán definitivamente su obra literaria entera: 1. La "afición a Grecia"; 2. El interés por los Siglos de Oro castellanos; 3. El amor a la sencillez, al desnudo artístico: en poesía, a lo esencial. Así, dice en el poema: "en el arte lo ingenuo tentarme pudo", y "yo prefiero la fresca flor de las pieles / y la mamila erecta por sólo escudo"; y, luego: "porque en la zampoña gimo y deploro / no revivir la gracia del siglo de oro / que confunde a la reina con la pastora". 8

De sabor clásico por su tono bucólico y que recuerda al Títiro de la égloga primera de Virgilio, es la "Oración pastoral" (1906). En seis estrofas combinadas de versos imparisílabos (alejandrinos y eneasílabos), trata de imitar un ritmo semejante al del "Responso a Verlaine", de Rubén Darío, y con el mismo orden de rima consonante: aab, ccb, según la primera edición de Prosas profanas (1896).

Esta "oración" es importante no por su intento métrico y por su motivo eglógico, sino porque se anuncia en ella el tema que se reiterará bajo diversas formas en la poesía de Reyes: el deseo de la calma en la búsqueda de lo bello, en consonancia con la vida y con la naturaleza, por medio de la armonía poética:

Mi labio en la zampoña suspira dulcemente, y va la vida rústica fluyendo como fuente

${ }^{8}$ Obras completas de..., op. cit., vol. X, p. 17. 
sobre su lecho de verdura;

$\mathrm{y}$, a las invitaciones de la naturaleza, aspiro en una onda de paz y de belleza

el solo aroma que perdura.

La clara preocupación por la expresión precisa de la emoción aparece por vez primera en su poesía como causada por la incomunicación incompleta de la naturaleza o de la incapacidad de la lengua para reproducir el contenido de su mensaje:

¿Cómo puedo explicarlo, si el viento no se explica ni se explican las voces del agua que salpica, ni los arrullos del follaje?

No hay voces ni hay acentos, murmullos ni rumores para imitar los cantos que gustan los pastores en esa música salvaje.

Y al vitalismo pánico del final del poema: “¡Amo la vida por la vida!", 9 que también se reflejará en el resto de su obra, sigue "Viñas paganas" (1906), poema que, en estrofas sáficas, es la invitación en boca de una joven pagana al viajero que pasa, si él desea oír "mi jónica voz que canta placer". ${ }^{10}$

El espíritu del poema es pagano, su léxico y sus imágenes son del modernismo, su metro es de imitación clásica. Ofrece interés también una estrofa que predice algo de su futuro "promiscuar en literatura", al que Reyes se referirá en su "Teoría prosaica" (1931), veinticinco años más tarde, al encarnar en un solo personaje lo mismo el refinamiento lírico que una cierta malicia terrena:

En mis huertos hay un rústico dios que al canto de Pan imita el vaivén y tiene la faz de sátiro y dos pitones también. ${ }^{11}$

\footnotetext{
${ }^{9}$ Ibid., p. 18-9.

${ }^{10}$ Ibid., p. 20.

${ }^{11}$ Ibidem.
} 
JOSÉ BARBA MARTÍN

"Lamentación bucólica" (1906) une a la forma de la quintilla tradicional (con rima ababa) una nostalgia del mundo arcádico pasado a través de una sensibilidad digna de la poesía del Siglo de Oro. En ese poema nos habla de su "taimado intento (de) volver / a las edades de oro"; y de su amor al "acento / de las dulces trovas de Dionisos"; y de su gusto por "la ingenuidad / de las canciones añejas".

Lugar particular en esta temática del mundo clásico de Reyes ocupan los siete "Sonetos ofrecidos a André Chenier" (1907), de intento y corte decididamente parnasianos, especialmente los sonetos sexto y séptimo. Alfonso Reyes, joven, admira a Chenier, y su sentido aristocrático de la poesía le trae el recuerdo del Horacio de la oda primera del libro III: Odi profanum vulgus et arceo; presenta "cómo el claro latino Chenier menosprecia la muchedumbre que le estorba el paso: va tras una visión, y entre gemidos clama altivando el rostro: ‘¡Grecia! ¡Grecia!'.”12 En el soneto cuarto, el poeta se aconseja a sí mismo: "Inspira tu cantar en las ligeras / coplas de Anacreonte." Y, al final del soneto, el tema ya iniciado que se repetirá muchas veces en su poesía: la elegante sobriedad: "a ver si resucitas con tu encanto / -ay, manes de Teócrito y de Mosco-/ la imperativa sencillez del canto".

El tema de la delicadeza necesaria a la poesía, tema que no desarrollará como poética más declarada sino hasta 1925 en "Arte poética", se insinúa ya en el soneto sexto. Dice así: "Tiembla un bosque de lauros. La quejumbre / de la avena canora se presiente / más que se oye".

En "Arte poética" nos hablará de la "asustadiza gracia del poema". "Filosofia a Lálage" (1910) descubre con claridad una nota que será definida en los poemas posteriores de Alfonso Reyes: un amor del decir en voz baja, de la suavidad del asilenciamiento, de algo que tal vez podríamos llamar un fértil quietismo poético. En dos cuartetos de alejandrinos recomienda el poeta a Lálage (del modo como Horacio, en su día, aconsejara a la joven Leucónoe; oda 11, libro primero) la quietud y el "noble silencio" como prudencia. Este poema - es oportuno anotarlo-corresponde a 1910, un año después de que Enrique González Martínez publicara Silenter. Reyes aconseja a Lálage: "Seamos por el noble silencio como el

${ }^{12}$ Ibid., p. 24. 
agua / quieta, que se enamora de su inmovilidad", y "apaga el ansia, baja la voz, filosofemos, / y no nos oiga el sueño lo que decimos de él. ${ }^{13}$

Este silenciar la voz ante el sueño predice la extrema delicadeza que recomendará más tarde ante la Eurídice dormida, su imagen de la poesía en "Arte poética", y que como aviso crítico se repite en prosa en la nota de introducción que Reyes escribe para su colección de poemas, bajo el título de Cortesía, la cual comprende los años que van de 1913 a 1958; en ella dice así: "Desde ahora te digo que quien sólo canta en / do de pecho no sabe cantar". ${ }^{14}$

Adelantándome un poco en la cronología, diré que este acallamiento consciente lo manifiesta Reyes más tarde claramente en "Silencio" (1943): "Escojo la voz más tenue / para maldecir del trueno / como la miel más delgada / para triaca de veneno"; y también: "a la barahunda opongo / el escogido silencio", pues añade, recordando por su bella formulación las famosas redondillas de Don Sem Tob, el rabino carrionés: "No es menor luz la centella / por durar sólo un momento, / ni es desamor el amor / que enmudece por intenso". ${ }^{15}$

Esta sensibilidad, como explicaré con mayor amplitud más adelante, responde a su concepto de la naturaleza misteriosa y esquiva de la poesía, por la cual el tacto del poeta sobre ella debe reducirse a lo estrictamente necesario. Esta cautela de fina concisión que debe tenerse con el poema obedece, como explica Alfonso Reyes en La experiencia literaria, a que "unas palabras crean, otras ni crean ni destruyen, y otras destruyen a fuerza de mucho crear". ${ }^{16}$ En el ya mencionado poema "Silencio", después de aconsejar: "cada vez menos palabras, / y cada palabra un verso; / cada poema un latido, / cada latido, universo", concluye con impaciencia: "déjate dormir, canción, / que ya duraste en exceso".

Alfonso Reyes justifica, de paso, esta economía verbal de la poesía al trazar un esbozo para una "Teoría de la antología", donde recomienda escoger los poemas "ante todo por sus dimensiones breves. Luego por su mayor condensación estética”. Porque, añade: "El poema es cápsu-

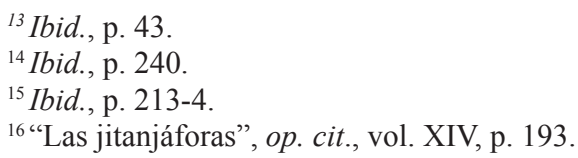


JOSÉ BARBA MARTÍN

la explosiva que junta en pequeñas dosis grande concentración de energía". ${ }^{17}$

La segunda etapa (años 1913 a 1924)

Este período es pobre en manifestaciones de credo poético. El poeta está fuera de la edad programática, y a la actividad natural de sus años (de los 24 a los 35) se une el movimiento de los viajes y la estadía en diversos lugares que, si ampliaban su experiencia humana, lo privaban del reposo interior necesario para la meditación y la formulación de intuiciones doctrinales. Con todo, las creaciones de estos años servirán más adelante como ejemplos, algunos excelentes, de la aplicación de sus principios artísticos.

\section{La tercera etapa (de 1925 a 1937)}

La primera formulación de arte poética, y bajo tal título, es del año 1925, que inicia el tercer período de la creación lírica de Alfonso Reyes. En "Arte poética", con brevedad intencionalmente paradigmática, en cuatro pareados endecasílabos de rima consonante, Reyes desvela la naturaleza de la poesía. Juan Ramón Jiménez escribió de ella: "No la toques ya más- que así es la rosa". Reyes, quizá recordando aquel verso de su estudiado y querido Góngora: "Amantes, no toquéis, si queréis vida", ${ }^{18}$ desea que la delicadeza sea mayor: la poesía es para él como una flor apenas entreabierta y sensitiva como la planta así llamada, la cual se cierra al menor tacto; que se insinúa apenas, como capullo. Ya en 1913, en su poema “¿Qué te diré?” Reyes había sugerido la imagen del capullo en esta cuarteta: "Y la canción contenida/ soñando con ser canción, / tiembla en átomos de vida / y vibra en germinación”. En eso cree

${ }^{17}$ La experiencia literaria, en op. cit., vol. XIV, p. 138.

${ }^{18}$ Góngora: soneto "La dulce boca que a besar convida", Sonetos Completos, Madrid, Editorial Castalia, 2001, p. 135. 
Reyes que está la gracia del poema: en su poder de íntima sugerencia, no en su total apertura:

Asustadiza gracia del poema:

flor temerosa, recatada en yema.

2

Y, se cierra como la sensitiva, si la llega a tocar la mano viva.

3

-Mano mejor que la mano de Orfeo mano que la presumo y no la creo,

4

para traer la Eurídice dormida hasta la superficie de la vida. ${ }^{19}$

Con ligera alusión, quizá intencional, a la "mano de nieve" que sepa arrancar las notas dormidas en las cuerdas del arpa, como al pájaro que duerme en las ramas, de la Rima VII de Bécquer, Reyes, con una imagen clásica, requiere del poeta que al bajar, como Orfeo al "infierno" de su propia intimidad, pulse la lira con finura suma, para rescatar íntegro el mensaje interior; como a la Eurídice dormida, a la vida plena de la expresión. Hay que notar que dice "dormida", que equivale a: dormida, no con valor descriptivo sino condicional; dormida: no porque ya lo esté, sino porque Orfeo (el poeta) debe rescatarla sin despertarla. Más tarde, en 1943, en una espinela que comienza así: "Quédate callado y solo", aludiendo, además, al origen inspirado de la poesía, Reyes completará este sentido: "y lo que cantas dormido / es tu canción verdadera". ${ }^{20}$

Es oportuno hacer notar aquí que ese "descender a los infiernos" interiores por parte del poeta estaría, al menos parcialmente, sugerido en aquel verso de Rubén Darío: “desde las sombras de mi propio

${ }^{19}$ Obras completas de A. R., vol. X, p. 247, y en vol. VII, apéndices.

${ }^{20}$ Op. cit., vol. X, p. 485. 
JOSÉ BARBA MARTÍN

abismo", ${ }^{21}$ pues el mismo Alfonso Reyes, en su prólogo a "Ifigenia cruel" (1923) habla de ese poema suyo tan querido como de "una flor que me hubiera brotado adentro", ${ }^{22}$ conjuntando en una sola frase la doble imagen poética. Vale observar, de paso, cómo Reyes usa la imagen de la bella durmiente del soneto "Yo persigo una forma...", de Rubén Darío, y tal vez con mayor acierto por estar, en la poesía de Reyes, más concentrado el símbolo. La influencia del simbolismo, que Reyes conoce y ha estudiado directamente en Mallarmé, se nota en la descripción de la poesía intacta que se rinde sólo al tratamiento impalpable y a la sugestión de la musicalidad interior.

Interludio: la "noche obscura" del poeta

"Arte poética” encierra en sí, juntamente, el problema de la emoción y el de la forma verbal capaz de "encarnar" el misterio poético. "Que en la poesía haya una comunicación de misterio - dice Reyes- es indiscutible. Los grandes poetas lo son porque logran captar el misterio en el arte. Si lo dejan escapar o si no llegan al equilibrio de la forma, se quedarán en las buenas intenciones, con que está empedrado el infierno". ${ }^{23}$ Se trata, sí, del misterio de una encarnación y de una epifanía; sólo que, al revés del misterio religioso según el cual "el Verbo se hizo carne", ${ }^{24}$ en el misterio poético es la substancia de la emoción la que, para manifestarse, se hace verbo. El uso de esta terminología teológica para tratar el fenómeno poético no necesita apología: de algún modo hicieron algo semejante Salomón, San Pablo, San Juan de la Cruz y, en nuestros días, Jacques Maritain y el mismo Alfonso Reyes, como se verá mas adelante.

El problema de la adecuación justa entre la emoción interior y la expresión perfecta - es decir, lograda- en el poema, lo trata Reyes en la composición inmediata a "Arte poética". Está en tercetos de rima

${ }^{21}$ Rubén Darío, Cantos de vida y esperanza, 1932, Madrid, Aguilar. Cfr. Obras Completas, p. 857.

${ }^{22}$ Op. cit., vol. X., p. 359.

${ }^{23}$ La experiencia literaria, en op. cit., vol. XIV, p. 232.

${ }^{24}$ San Juan, Evangelio, 1, 14. 
asonante y corresponde al mismo año, 1925. "Jacob” se publicó en el libro La vega y el soto, en 1946; como Bécquer en la Rima primera: "Yo sé de un himno gigante y extraño"; como Rubén Darío en su soneto "Yo persigo una forma que no encuentra mi estilo", de Prosas profanas, Reyes expresa también la "inutilidad" del esfuerzo por aprehender la forma y expresión definitivas que den exactamente el contenido de su experiencia íntima. Es como una "noche oscura" del poeta -"disolución del espíritu" la llama Reyes en uno de sus ensayos-, ${ }^{25}$ noche que Bécquer y Reyes mencionan directamente; el primero: "Yo sé de un himno gigante y extraño / que anuncia en la noche del alma una aurora"; el segundo: "Noche a noche combato con el ángel...", ${ }^{26}$ y que Rubén Darío sólo sugiere por medio de elementos asociados con la noche: "el ave de la luna sobre el lago tranquilo" y "la barca del sueño que en el espacio boga". El tema de "Jacob" parece que lo toma Reyes de esos dos poetas; la imagen-símbolo, de la Biblia: el primer sueño de Jacob:

Quedóse, pues, Jacob, solo. Y un hombre estuvo luchando con él hasta rayar el alba. Como viese que no le podía, alcanzóle en la articulación del muslo y se descoyuntó la articulación del muslo de Jacob mientras peleaba con él. Entonces dijo el personaje: "Déjame marchar pues raya el alba". Respondió Jacob: "No te dejaré partir sino cuando me hayas bendecido”. Y él le preguntó: “¿Cuál es tu nombre?”Y le contestó: “Jacob”. Entonces aquél afirmó: "Ya no es tu nombre Jacob sino Israel, pues has luchado con Dios y con los hombres, y has salido victorioso". ${ }^{27}$

La distinción de los dos nombres: Jacob-Israel parece contener el símbolo del poeta antes y después del logro de la expresión poética. Jacob es el poeta que lucha con el ángel, mensajero de la inspiración, para lograr quitarle el mensaje. Israel sería, pues, el poeta que ha logrado expresar el contenido de la inspiración. También el tema del combate por la expresión queda declarado en Bécquer: "pero en vano es luchar". Reyes

25 "Apolo o de la literatura", op. cit., vol. XIV.

${ }^{26}$ Op. cit., vol. X, p. 113.

${ }^{27}$ Génesis, XXXII, 24-8. 
JOSÉ BARBA MARTÍN

dice: "Noche a noche combato con el ángel". Que la experiencia es dolorosa lo dicen los versos segundo y tercero del primer cuarteto: " $\mathrm{y}$ llevo impresas las forzudas manos / y hay zonas de dolor en mis costados". La inutilidad del esfuerzo, en Bécquer: "pero en vano es luchar", Reyes la expresa así: "Quiere correr a consunción mi sangre / y aunque sé que en su busca me deshago, / otra vez lo persigo y lo reclamo."

El poeta "aúlla", es decir, se expresa mal, pero dentro de sí mismo "está cantando": posee la emoción substantiva de la poesía. La forma huidiza que Darío persigue en el soneto mencionado es para Reyes una "nube grave" la cual alude, como aclara el poeta en su ensayo "Jacob o la idea de la poesía" (1933), a la ilusión con que Ixión fue engañado por la diosa Juno disfrazada de nube.

La dificultad de la poesía surge -dice Reyes en su ensayo-de que "las veces, y aun las más de las veces lo que necesita y lo que quiere [el poeta] es expresar emociones imprecisas. Como que la poesía misma nace del afán de sugerir lo que no tiene nombre hecho". Pero aun entonces, "el poeta debe ser preciso en las expresiones de lo impreciso. Nada se puede dejar a la casualidad. El arte es una continua victoria de la conciencia sobre el caos de las realidades exteriores. Lucha con lo inefable: 'combate de Jacob con el ángel' lo hemos 1lamado". ${ }^{28}$ También en el ensayo titulado "Apolo o de la literatura", al insistir en la distinción esencial entre el estado subjetivo de la emoción poética y la poesía como ejecución verbal, Reyes pide al poeta que acepte su sino, que es combatir como Jacob con el ángel. "Es la lucha - dice- con lo inefable, en la desolación del espíritu, como Ixión”, pues añade más adelante: “el lenguaje no está acabado de hacer. No lo estará nunca”; por lo cual, como afirma con la cita de Paul Valéry, "la poesía intenta crear un lenguaje dentro del lenguaje". ${ }^{29}$

Es San Juan de la Cruz el gran poeta de la doble "noche oscura": la del alma que busca a Dios y la del artista que busca la expresión. En su prólogo al Cántico espiritual, proclama "la esencial inefabilidad de la poesía, o, más exáctamente, de su origen, del estado pre-poético". ${ }^{30}$

${ }^{28}$ Obras completas de A.R. , op. cit., vol. XIV, p. 103.

${ }^{29}$ Op. cit., vol. XIV, p. 85 ss.

${ }^{30}$ San Juan de la Cruz, Cántico espiritual, "La noche oscura", 2, XVII. 
Esta dificultad, que es particularmente intensa en la poesía de San Juan de la Cruz, por tratar de expresar algo que no se ha percibido por los sentidos sino en la contemplación interior, no es, sin embargo, diferente en su esencia de la experiencia del poeta laico, pues también éste intenta expresar la irrepetible emoción "de una cosa nunca vista, cuyo semejante tampoco jamás vio". ${ }^{31}$ Lo que es el Amor para el poeta místico propiamente dicho es la emoción intensamente sentida para el poeta laico. Y, "como el lenguaje requiere tantas condiciones lógicas, algo de lo que no es pensamiento racional no puede encajarse en frase o el discurso". Así, "la necesidad de la poesía surge de esta inevitable imposibilidad de hallar equivalencia en las palabras". ${ }^{32}$ Rebasando el lenguaje sus límites intelectuales, los únicos atisbos de los "secretos misterios" pueden darse sólo por medio de la circunlocución poética. Reyes completa el concepto: "Los atisbos buscan la coherencia. Y la razón asume su verdadero servicio, limitándose a ponerlos en orden": ${ }^{33}$

Nuestra operación sería la inversa: consistiría en desandar ese camino; en comenzar por el poema -boca de embudo de Bergson, en sus disquisiciones sobre la materia y la memoria- y marchar hacia atrás desandando los procesos de que el poema viene a ser como el lazo último. (La experiencia literaria).

La tercera etapa de la creación literaria de Reyes (1925-1937), y cuyo principio tratamos en la primera parte de este trabajo, tal vez sea la más abundante en manifestaciones aprovechables para una teoría poética: nueve poesías, la cuarta parte del conjunto de este período, la tratan abierta o semiveladamente. No es de sorprender, si observamos que el poeta ha dejado ya la extrema juventud (en 1925 tiene treinta y seis años) y alcanza una lograda madurez (en 1937 tiene cuarenta y ocho años). Es ésta, sin duda, una época de creación reflexiva y en la que los estudios crítico-filológicos de Reyes sobre la poesía de Góngora, por ejemplo "Sabor de Góngora" (1928), ${ }^{34}$ debieron contribuir a hacer

${ }^{31}$ Jorge Guillén, op. cit, p. 91.

${ }^{32}$ Idem., p. 93.

${ }^{33}$ Alfonso Reyes, "Del conocimiento poético", en Alyunque, 1960, México, Tezontle, p. 12.

34 “Cuestiones gongorinas”, en Obras completas de A.R., vol. VII, p. 171-98. 
JOSÉ BARBA MARTÍN

a nuestro autor más consciente de algunas de sus propias tendencias artísticas. También en esta época, aunque es mucha su variedad, los temas se hacen más íntimos, y son muchos los que ya se alimentan del recuerdo, sobre todo aquellos que Reyes escribe hacia la cincuentena, como corresponde, quizá, a quien esta más allá del "mezzo del camin..." $" 35$

El perfume del poema parece aflorar en su alma ante cualquier circunstancia. En "Apenas" (1927), -tres redondillas con rima asonante: abab-, Reyes lo sugiere así: "A veces, hecho de nada, / sube el efluvio del suelo. / De repente, a la callada, / suspira de aroma el cedro", idea que repetirá, pocos años más tarde, en un artículo sobre Mallarmé, al decirnos: "Cada instante entrega, sin sobresaltos ya, su secreto". ${ }^{36}$ En el poema citado continúa: "Somos como la delgada / disolución de un secreto, / a poco que cede el alma / desborda la fuente un sueño...". ${ }^{37}$

Con lo cual Reyes no se contradice, diciendo que el poema sea fácil, sino que indica cuán cargada de inspiración lleva el alma. Las palabras "secreto" y "sueño" nos señalan que se trata del sentimiento en sí, no necesariamente de su expresión: "no confundamos la provocación con la ejecución artística -nos previene Reyes, al tratar de "Los estímulos literarios"-; no confundamos la emoción con la poesía misma". ${ }^{38}$ "Cacería divina" (1931) es a un tiempo continuación de la poética de Reyes y un ejemplo de su cosmopolitismo literario de humanista moderno, cuya sensibilidad le impide alejarse totalmente de las experiencias contemporáneas. Bajo estructura de soneto con rima abba, abba, bbc, ccd, (asonante), y con empleo de imágenes al gusto del Creacionismo o de la Vanguardia, repite Reyes el tema de la dolorida pero gozosa creación del poema, que ya vimos en "Jacob" (1925) y que hallaremos de nuevo en el poema "San Sebastián" (1933). En "Cacería divina”, se menciona al poeta, sin verdadera configuración, como un extraño ser

35 “Andada más de la mitad del camino", escribe A. Reyes a E. Diez-Canedo y a Genaro Estrada desde París, en 1926, al nombrarlos albaceas literarios suyos (aunque fallecieron antes), cf. op. cit., vol. IV, p. 475 y p. 482, nota.

${ }_{36}$ "Culto a Mallarmé”, en Sur, Buenos Aires, IV, núm. 9, 1933.

${ }^{37}$ Obras completas de A.R., op. cit., vol. X, p. 120.

${ }^{38}$ En "Tres puntos de exegética literaria", op. cit., vol., XIV, p. 296. 
cósmico que retoza y revolotea "en el viento hecho palabras", con las que él mismo ha poblado "la campana hueca del cielo". Palabras -hay que observar- que todavía no forman frase. El ser cósmico "se mecía en la luz como entre espadas, / azuzaba con voces las estrellas, / amanecía con locuras nuevas / y dormía celado de fantasmas". ${ }^{39}$

En estos versos, un mero subrayar de intención léxica nos indica la paternidad de un concepto y de una imagen: "Las locuras nuevas", con que le llega la mañana a ese ser, nos recuerdan, quizá, la theia epípnoia de la teoría sobre la inspiración poética del Ión de Platón, que hallamos bajo discernimiento y formulación diferentes en otros de sus poemas. Por ejemplo, en "Quédate callado" (1943), dice: “y lo que cantas dormido (=inspirado) es tu canción verdadera." El dormir "celado de fantasmas", por otra parte, nos hace retroceder otra vez a la "extravagante procesión" de "fantasmas sin consistencia" de la febril inspiración becqueriana a que se refiere el poeta romántico en su "Introducción" de 1868 a las Rimas. En el fondo, la misma ambigüedad de violencia y lucha que vimos en "Jacob" se repite en "Cacería divina". En ese poema, Jacob (el poeta) combate con el ángel para arrebatarle el mensaje y, al final, quiere ser vencido para que de su pecho sangrante brote el poema. En "Cacería divina" nos dice Reyes que: "En el aire se juntaban fuerzas, / tretas de cazador, silvos de flechas". ¿Son, tal vez, los esfuerzos del poeta por captar la expresión justa, la formulación perfecta, la imagen insustituible? ${ }^{40} \mathrm{Y}$ el ser que "lame el asta" con que es atravesado, "sin sollozo", y mira "sonriendo el bronco / árbol que salta de su corazón”, ¿no es el poeta mismo? ¿Y no parece evidente al buen lector en esta imagen la presencia del poema gongorino en "dedicatoria" al Duque de Béjar: "del oso que aún besaba, atravesado, / el asta de su luciente jabalina"?

¿Y es difícil reconocer en esa asta que le atraviesa el corazón y se convierte en árbol el símbolo del poema mismo, sobre todo si tenemos en cuenta el corte casi creacionista de esta poesía y recordamos el consejo de Vicente Huidobro: "hacer crecer, como un árbol, el poema"? En todo

${ }^{39}$ Op. cit., vol., X, p. 130.

${ }^{40}$ Cómo se verá, esta imagen la toma Reyes de la "Dedicatoria" de las Soledades al Duque de Béjar. 
JOSÉ BARBA MARTÍN

caso, la cacería es divina porque el objeto de la misma es el numen poético o porque el dios de la inspiración debe rendir al poeta a la forma de expresión necesaria.

Reyes reitera también el forcejeo implícito que en la creación poética se entabla entre el poeta y el objeto de su creación. En "Arma virumque (El creador literario y su creación)", cita a Jean Cocteau: "Cocteau dice que el poema detesta al poeta. Uno de los dos tiene que acabar con el otro. De aquí que el escribir sea un sistema de conservación, de defensa". ${ }^{41}$ Otra cita de Reyes esclarece quién es el cazador y qué es lo cazado. En "La poesía desde afuera", al hablar el autor de la rebeldía del poema a someterse a conceptos, dice: "La poesía seguirá volando, indemne, por su cielo enrarecido y alto. Para darle caza hay que ser poeta". ${ }^{42}$ Como variante de la misma idea, escribe Reyes en su "Epílogo" a la antología de la Prosa de José Gorostiza:

El escritor persigue hasta la exasperación la palabra precisa, y en la misma creación poética hay un acecho, una pugna como de combate de cacería. Por mi parte dije alguna vez que es una lucha de Jacob con el Ángel esta guerra, para "crear un lenguaje dentro del lenguaje", duelo en que el poema nos mate o nosotros lo sometemos -"le damos mate"-: y en metáfora más humilde, como se ha escrito, un cortar hilo por hilo todas las amarras del aeróstato, para que el poema se eleve solo, y solo se defienda entre los acosos del viento. ${ }^{43}$

"San Sebastián" (1933) es el tercer poema que, junto con "Jacob" y "Cacería divina”, forma la tríada que confirma el concepto de Reyes sobre la gestación lírica como la ambigua experiencia de dolor-placer, odio-amor, muerte-vida, a la cual hemos aludido antes en este trabajo. Ya en "Los pavos de mi infancia" (1913), ${ }^{44}$ por veintiún años anterior a "San Sebastián", el joven Reyes había dado un "avance" de su particular idea sobre el modo de la génesis artística en la poesía, al identi-

${ }^{41}$ Al yunque, op. cit., p. 36.

${ }^{42}$ Ibid., p. 81.

${ }^{43}$ José Gorostiza, Prosa, 1969, México, Universidad de Guanajuato, recopilación, introducción, bibliografía y notas por Manuel Capistrán, p. 245.

${ }^{44}$ Publicado en Huellas, 1922, Madrid, Biblioteca Nueva. 
ficarse -con súbito cambio de vista-con el elegante animal al que él mismo, imaginariamente, estrangula, es decir, posee:

Garganta tersa que a estrujarla incita; pico anhelante, exacto y sibarita, hendido y fácil para que permita que sangre el ave cuando el pecho grita el grito que oigo renacer en mí. ${ }^{45}$

Prefigurando, en cierto modo, el martirio de su "San Sebastián”, en la estrofa penúltima, y consumando ahora el cambio de papeles: de torturador a víctima, que el grito inicia, el poeta ruega así al pavo real, que encarnó para el niño Reyes su primera intuición estética:

Ave, el ventalle de tus plumas ábreme.

Ave, las púas de tus gritos clávame y sean dardos que vibrando graben cifras y letras en mí corazón.

¡Así, al cantar, el corazón me labres, para que sean joyas mis palabras...!

En su ensayo "Los pavos", al recordar la hermosura de los que, siendo niño, había criado en su huerta de Monterrey, Alfonso Reyes escribe: "Aquello fue un 'pregusto' de la estética gongorina, cuando yo aún no sospechaba al gran poeta cordobés, ni menos se figuraba lo mucho que había de trabajar en torno a su obra. Mi vocación se iba encaminando oscuramente."Y, más adelante, al mencionar sus poemas "Los pavos de Susana" y "Los pavos de mi infancia", añade: "Ellos, como quiera, dan testimonio de mi fidelidad a la imagen del pavo, estampada profundamente en mi memoria como un maravilloso chisporroteo de colores y de tañidos."

En "San Sebastián”, al igual que en "Jacob” y en "Cacería divina”, el poeta contrapone también dos elementos que en su psicología personal y en su imaginación poética son de mutua necesidad artística: el mártir y el verdugo. Lo que en "Cacería divina" era un extraño elemen-

${ }^{45}$ Obras completas de A.R., op. cit., vol. X, p. 489. 
JOSÉ BARBA MARTÍN

to, primero informe y luego zoomórfico, se antropomorfiza en "San Sebastián”. El mártir u objeto de la cacería es aquí, más claramente, el poeta, que, herido por "las temblonas pestañas de las flechas" -es decir, por los estímulos sensibilizadores de la experiencia humana-rinde generosamente "la dulce sangre, la lenta gloria" interior de la expresión [del poema], "que sólo anhela ser vertida". Estos flechazos, tal como esclarece Reyes en su ensayo sobre "Los estímulos literarios", son el chispazo, el principio del prólogo al proceso de la creación poética:

La primera palpitación de este movimiento [...] Acontecen todavía en el ser del poeta y son anteriores al primer trazo de la pluma. Carecen aún de realidad fuera del yo, aun cuando los provoquen objetos reales y exteriores. Son un latido vital anterior al arte. [...] Se trata de estímulos (positivos) que lo mismo pueden venir de la vida que de los libros, de la emoción como de la reflexión, del trato humano o de la rumia solitaria, de la reacción ante las otras artes y hasta de un achaque de salud, ${ }^{46}$ de lo grande como de lo humilde [...] En el lenguaje de Loeb, el poema es el 'tropismo' con que el ser poético responde al estímulo. ${ }^{47}$

Así, según Reyes, se conjunta en orden causal la experiencia humana general con la experiencia literaria concreta. En la página blanca, como la sangre sobre el cuerpo del mártir asaeteado, el poema se va "calcando afuera en cifras rojas", expresando "todo el hervor de mis entrañas mudas". Como en la estética de Reyes cazador y presa, verdugo y víctima son, aunque contrapuestos, complementarios, la misma idea de extraño, placentero agradecimiento con que, en "Cacería divina" el animal, atravesado por el asta, la besaba, queda repetida y confirmada en "San Sebastián" por la "dolencia natural de varonía", por la "virtud que sólo anhela ser vertida". ${ }^{48}$

Es interesante observar que esta reiterada idea de Reyes sobre la creación poética como voluntario forcejeo, anhelada violencia y desea-

${ }^{46}$ Véase, por ejemplo, en el mismo A. Reyes, "La corona", poema de 1938, que parece proceder de la impresión que le causó un ataque cardíaco, op. cit., vol. X, p. 464.

47 “Tres puntos de exegética literaria”, op. cit., vol. XIV, p. 267 ss.

${ }^{48}$ En su soneto número 57, dedicado a Mariano Brull, de Jornada en sonetos (1912-1956), Reyes dice: "Mariano, así nació la poesía: / humo de sangre que la vida exhala / y luego se depura todavía / y asume voz al remontar el ala”, op. cit., vol. X., p. 458. 
da lucha no es nada ajena, por su propia substancia y por su expresión de naturaleza oximorónica, a la idea de la pasión amorosa, tal como la recibimos desde Longino (Perí Hypsous), pasando por el diálogo De gratis amoribus, ${ }^{49}$ de Petrarca: "Est enim amor latens ignis, gratum vulnus, sapidum venenum, dulcis amaritudo, delectabilis morbus, iucundum supplicium, blanda mors..." y que nos llega a la literatura castellana del primer Siglo de Oro en la poesía amorosa de Garcilaso; en la mística, con los escritos de Santa Teresa y, cultamente, sobre todo en San Juan de la Cruz: "Oh, llama de amor viva / que tiernamente hieres!”, "¡Oh, cauterio suave! ¡Oh regalada llaga!"50

De este entendimiento del estímulo literario en su relación substancial y analógica con el amor Reyes habla bien claramente en una respuesta de sus Simpatías y diferencias. Dice así: "Es un anhelo que se parece tanto al amor. Los físicos (es decir, los médicos) demostrarían fácilmente que, cuando llega el apremio de escribir, hay palpitaciones cardíacas semejantes al sobresalto amoroso e iguales descargas de adrenalina en la entraña romántica". ${ }^{51} \mathrm{Y}$, al hablar de su obra literaria: "Hoy por hoy, no sé ya qué pienso de mis libros escritos. Estoy ocupado, torturado y gozoso, con los que llevo dentro". ${ }^{52}$ También, en sus Tres Puntos de exegética literaria, nos recuerda que el instante del genio es un "hecho tan de la naturaleza que hasta participa del placer biológico. [...] No sólo la concepción de la obra en su conjunto o siquiera en su arranque, hasta la diminuta conquista de una palabra que se anhela y se busca produce palpitaciones entrañables y a veces trae lágrimas a los ojos". ${ }^{3}$ Y, para continuar con esta implicación de analogía erótica, adelantándose con varios años (en El cazador, 1921) a la parábola de Paul Claudel "Animus et anima" (Nouvelle Revue Française, 1925), expresa Reyes el encuentro conflictivo-armonioso necesario para la creación poética, en

${ }^{49}$ Igual sentido oximorónico expresa Alfonso Reyes en el soneto dedicado a Mariano Brull: "Sus raudos hijos la palabra cría: / risas y llantos en el trino iguala. / Siendo victoria, vive de agonía / y se agota de austera, siendo gala. / Dureza blanda, eternidad ansiosa, / tesoro esquivo pero nunca vano, / fugitivo cristal, perenne rosa."

50 "De remediis utriusque fortunae", Dialogus XLIX.

${ }^{51}$ Obras completas de A. R., vol. IV, p. 451.

${ }^{52}$ Ibidem.

53 “Los estímulos literarios", op. cit., vol. IV, p. 268. 
su pesadilla simbólica titulada "Diálogo de mi ingenio y de mi conciencia”. En este diálogo el yo del poeta se escinde, ante sí mismo, en dos seres: uno, "todo ímpetu" (el ingenio); el otro, "todo derrota" (la conciencia), siendo el ingenio hombre, y la conciencia mujer, que, a los galanteos de aquél, se le rinde llorando; seres ante los cuales el poeta, después de gritar - en vano- "iQué imposible maridaje es éste!”, constata que "aquellos dos fantasmas, el varón dotado de alas y la hembra armada de cuchillo, se reproducían en una numerosa prole de gnomos", ${ }^{54}$ todos parecidos al poeta. ${ }^{55}$ Así que de ese ambiguo encuentro, acto amoroso y lucha, brota el poema; el poeta vence cuando logra dar a la emoción su transparente forma exacta.

En el contexto de esta interpretación, "Consagración" (1934) es un epinicio personal, un canto de triunfo con que el poeta celebra la captura de la intuición en las redes de la expresión perfecta y definitiva. Apostrofando al momento hecho poesía, exclama:
¡Aquí te sujeto yo!:
Ya no pedirás albricias, mitad del conocimiento, que te hice de cristal para siempre.
Ya verás, mitad del día, ya verás, mitad del tiempo, lo que vale ser recuerdo para siempre. ${ }^{56}$

Y, confirmando lo dicho antes sobre la inevitable eliminación entre el poeta y el poema, en un pareado de arte menor: "Ya no corres ni te vas: / te matamos, te maté...". Que Reyes apostrofa verdaderamente a la poesía en este poema no tiene duda, pues en el segundo verso de la primera cuarteta, de pie quebrado, se refiere a la "mitad del conoci-

${ }^{54}$ De nuevo, en el soneto dedicado a Mariano Brull: "sus raudos hijos la palabra cría", op. cit., vol. X, p. 458.

${ }^{55}$ Op. cit., vol. III, p. 203.

${ }^{56}$ Idem, vol. X., p. 133. 
miento", cuya teoría desarrolla en su ensayo "Del conocimiento poético", que contrapone al conocimiento racional y llega, incluso, a considerar como una etapa de la mística o parte de la mística misma. ${ }^{57}$

Para el delicado poema siguiente, adelanto aquí una observación que también encajaría en la última sección de este trabajo: me refiero al hábito reyiano de utilizar frecuentemente recursos de índole culta-popular, como los acertijos versificados. Poseemos en castellano todo un "adivinancero", ya bien estudiado, caracterizado, categorizado, que recorre toda nuestra literatura desde los tetrástofos monorrimos de la “cuaderna vía”, pasando por "enigmas filosóficos" del siglo XVII y de adivinanzas cultas "a lo divino", hasta las adivinanzas dialogadas de Miguel Hernández y las actuales del rico acervo hispanoamericano. ${ }^{58}$ En "Adivinanza" (1931), de Cortesía, poema dedicado a Francis de Miomandre para agradecerle su libro de poemas Samsará, Reyes toca el tema de la intuición poética aludiendo otra vez a la imagen de la Eurídice dormida que hallamos en "Arte poética” (1925). Aquí, en la forma que sugiere el título del poema, el poeta pregunta:

$$
\begin{aligned}
& \text { ¿Qué será? ¿qué no será? } \\
& \text { Asoma, y pasa, y se va } \\
& \text { ¿Quién me lo adivinará? }
\end{aligned}
$$

${ }^{57}$ Al yunque, op. cit., p. 10 ss. Es interesante notar, como curiosa coincidencia, que el ensayo de Reyes se publicó en enero de 1944, en el mismo mes y año en que Jacques Maritain dio una conferencia sobre "La experiencia poética" en la Universidad de Chicago, y que sólo se imprimió como artículo diez meses más tarde, en The Review of Politics, IV, octubre, 1944. Y no es sino hasta 1952 cuando Jacques Maritain da, en la National Gallery of Arts de Washington, las seis conferencias que forman su Creative Intuition in Art and Poetry (1953, NewYork, Pantheon Books). Sería de suponerse que Alfonso Reyes conocía Frontières de la poésie et autres essays (Paris, 1933) y Situation de la poésie (1938), de Maritain, el primero, y de este autor y de Raïssa, su esposa, el segundo; pero no tenemos la certeza de que Reyes conociera esa obras. Alfonso Reyes participó con Jacques Maritain, Francisco Romero, Pedro Henriquez Ureña, Georges Duhamel y otros autores en la VII Conversación del Instituto Internacional de Cooperación Intelectual, que se desarrolló en Buenos Aires, en septiembre de 1936. Pero de las tres veces que en sus Obras Completas Reyes hace referencia a Maritain, ninguna es por causa o en relación con la poesía. Cabe, desde luego, pensar en fuentes filosóficas y literarias comunes a ambos: en el pasado lejano, las Eneadas, de Plotino; y en aquel pasado, inmediato para Alfonso Reyes, Henri Bergson, Les données immédiates de la conscience (París, 1889), L'intuition philosophique (Paris, 1911); y de Paul Valéry, Eupalinos, de 1923, que estudia al hombre como la frontera del espíritu y la materia.

${ }^{58}$ José Luis Garfer y Concha Fernández, Adivinancero Culto, 2000, Madrid, Edimat Libros. 
En el filo de la vida una Eurídice dormida. ¿Quién me lo adivinará?

Razonable sinrazón, música que hurta el son al tiempo que lo prodiga, ${ }^{59}$ flor sin tallo y sin espiga: ¿Qué será?

Entre juguetón y reflexivo, Reyes inquiere, al tiempo que da los elementos indispensables del acertijo. Dando al segundo verso de la primera tercerilla un cierto aire de aforismo heraclíteo: "Asoma, y pasa, y se va", Reyes alude al carácter huidizo y sutil de la intuición, y mucho más veladamente que en "Arte poética" -pues se trata ahora de una adivinanza- sugiere la absoluta necesidad de ofrecer a la intuición un atentísimo cuidado. Recuerda esos libros espirituales a los que se refiere Ernest Dimnet en su The Art of Thinking, en los que "se cita a veces un dicho latino que ha infundido temor a más de un alma: Time Jesum transeuntem et non redeuntem, "teme el paso de Jesús, porque no vuelve"; como si quisiera decir: "No dejes que se te escapen las intuiciones (religiosas), por que no se repiten". ${ }^{60}$ Reyes diría, desde luego, que "es una exageración decir que las intuiciones, de cualquier clase que sean, no vienen por segunda vez", pero estaría de acuerdo en afirmar que "no llaman dos veces con la misma voz" ${ }^{61}$ Como prueba de esto, y con la misma idea de la adivinanza, tomamos como ejemplo el cuarto de los cuatro romances que casi concluyen el período de la poesía que nos ocupa. En este romance, de aire machadiano, el poeta pregunta a su alma: “¿Qué tienes, alma, que gritas / a tu manera y sin voz?; a lo cual responde el alma, quejándose de lo que conoció y le desapareció de su vida:

Vi una torre, vi una fuente, vi una mujer, vi una flor,

${ }^{59}$ Observamos aquí, nuevamente, el sentido oximorónico tan frecuente en Reyes, con algo de barroquismo; la oposición entre la fe y la razón de la inteligencia (o entre corazón y razón); y también la alusión a "la música callada, la soledad sonora".

${ }^{60}$ The Art of Thinking, 1942, New York, Pocket Books Inc., p. 171.

${ }^{61}$ Al yunque, op. cit., p. 10 ss. 
sentí una canción, vi un ave, adiviné un resplandor. La torre se iba rindiendo, se agotaba el surtidor, mujer y flor se mudaban perdiendo aroma y color, el ave se estremecía: ya no volaba, ya no; y el resplandor que pasaba, ¿Dónde se fue el resplandor?

Resplandor, es decir, aquella intuición. Esta inquietud por no dejar que se escape la intuición es evidente sobre todo al final de este período poético (1925-1937), que es ya, como dijimos, el de la reflexión y del recuerdo. En la tercera de sus cuatro "Soledades" (hay que reparar en el título por lo que tiene de clásico y de sentido), el poeta habla de esa inquietud interior que le hace concentrarse en el "último refugio" de sí mismo, "para juntar mis pedazos", (el subrayado es mío), para "este acordarme de mí / que se me quiere olvidar"; para "ordenar y contar" y un "llorar" nostálgico que le acerca dolientemente a la oda catorce del libro II de Horacio: Eheu fugaces, Postume, Postume, labuntur anni, (“Ay, cuán rápidos, Póstumo, mí Póstumo, se nos resbalan los años”), y que Rubén Darío, el de cuarenta años - más joven entonces que el Alfonso Reyes de estos poemas, pero físicamente más consumido- expresa en su poema justamente titulado "Eheu" (de El canto errante, 1907). En él Darío cree interpretar "unas vagas confidencias / del ser y del no ser / y fragmentos de conciencias (el subrayado es mío) / de ahora y de ayer". Darío habla de sus "fragmentos de conciencias"; Reyes, de ese "juntar mis pedazos", es decir, recuerdos, atisbos de la memoria, estímulos del tiempo pasado. Darío dice: "El conocerme a mí mismo / ya me va costando / muchos momentos de abismo". Reyes, con menos sentido trágico, pero no con menos lirismo, en tono casi de suave confidencia, habla de ese "acordarme de mí / que se me quiere olvidar".

También se trasluce, en estas cuatro "Soledades" de Reyes, la pena interior por la juventud que se va -que se ha ido- "para no volver", 
de esa autoelegía que es la "Canción de otoño en primaveral", de Darío (Cantos de vida y esperanza, 1905). El mismo “dolorido sentir", como expresó Garcilaso, con mayor equilibrio en Reyes, pero no con menor melancolía. En la primera de las cuatro "Soledades", el poeta se pregunta a dónde se han ido cuatro símbolos de su juventud:

Cielo y mar, sonrisa y flor, ¿dónde estáis y dónde estoy? ¿dónde la secreta dicha que corría sin rumor?

Y, como quien engarza una perla ajena en el broche propio, con evidente valor de evocación, escribe: “¿Qué se hizo el Rey Don Juan, / los infantes de Aragón? (¿qué se hicieron?) [...] / ¿dónde estáis y dónde estoy?" Los versos de Jorge Manrique pasan de una melancolía a otra melancolía, cobrando renovado valor en la íntima revelación personal.

\section{La función del recuerdo como estímulo literario}

La ambivalencia que hemos hallado al tratar de la génesis poética se encuentra también en la concepción que Reyes tiene del recuerdo como estímulo literario. En un poema del mismo año de sus "Soledades" (1937) Reyes escribe, para el libro de Monina: ${ }^{62}$

Una misma melodía cantada en distinta edad:

aprender-Realidad, desaprender-Poesía.

Que hoy disfrute a saciedad cada flor y cada ave: mañana como la nave de Molinos, ya en el puerto,

62 “Poesía y Realidad”, Obras completas de A. R., op. cit., vol. X, p. 278. 
recoja el velamen muerto

y abandone lo que sabe. ${ }^{63}$

Con todo lo cual, Reyes parece sugerir que la poesía es, por una parte, fijación: el “iAquí te sujeto yo!”, de "Consagración”, y, por otra, olvido: como si el poeta, al escribir de esos pedazos o fragmentos de su propio pasado, se aligerase de una vida anterior, tal como en la creencia griega las almas de los muertos lavaban su memoria bebiendo las aguas del río Leteo. Valle-Inclán lo expresa a su modo en las citas que damos al pie de esta página. El quietismo sugerido por Reyes, al hablar también de la nave de Molinos, subraya ese desposeimiento de la facultad mental y es específico en los versos "recoja el velamen muerto / y abandone lo que sabe". Sin embargo, con la ambivalencia que ya hemos visto frecuentemente en Reyes, éste reconoce también que es por medio del recuerdo como él establece un nexo de continuidad en la propia vida. En su soneto titulado "Virtud del recuerdo", de doce años más tarde (1949), dice:
Me desesperan los torcidos trazos, en la madeja del azar me pierdo y pugno por soltarme de los lazos.
Pero renazco vencedor y cuerdo, porque juntan y zurcen los retazos los virtuosos hilos del recuerdo. ${ }^{64}$

${ }^{63}$ En estos versos Reyes sigue literalmente la doctrina estética de Valle-Inclán. En Cartones de Madrid (1914-1917), en la reseña que hace Reyes de una conferencia de "Valle-Inclán, teólogo", dice: "[Valle-Inclán] aconseja olvidar, después de aprender y conocer, para no conservar más que el olor del conocimiento. Hagamos - decía el quietista Miguel de Molinos en el siglo XVII- como la nave que, llegada al puerto, olvida el oficio de la vela y del remo", op. cit., vol. II, p. 85. Valle-Inclán, como es sabido, expone su doctrina más formuladamente en La lámpara maravillosa (Ejercicios espirituales). Algunas de sus ideas clave en relación con el punto que tratamos aquí son: "El quietismo estético tiene una fuerza alucinadora. Inicia una visión más sutil de las cosas, y al mismo tiempo nubla su conocimiento porque persiste en ellas el misterio", 1948, Madrid, Espasa Calpe, Col. Austral, núm. 811., p. 105. "Ninguna cosa del mundo es como se nos muestra y (que) todas acendran su belleza en los cristales del recuerdo, cuando se obra la metamorfosis de los sentidos en la visión interior del alma", op. cit., p. 109.

${ }^{64}$ Obras completas de A. R., op. cit., vol. X, p. 444. 
No es de sorprender esta actitud en la poética de Reyes. Él mismo, en otro poema anterior al ciclo que aquí comentamos, en el soneto "Años después" (1923), había señalado escuetamente la causa: "las distancias fundan diferencias". Diferencias en el hombre y en la perspectiva interior de su sensibilidad. Esto quedaría confirmado por la experiencia poética de otros grandes artistas literarios españoles. Así Bécquer, de quien ya hemos hallado trazos en Reyes, escribe en la segunda de las Cartas literarias a una mujer: "Todo el mundo siente; sólo a algunos les es dado el guardar como un tesoro la memoria viva de lo que han sentido; yo creo que estos son los poetas. Es más, creo que únicamente por esto lo son."

Antonio Machado, quien, mientras traducía para la editorial Gallimard, aprovechó una estancia en París para escuchar conferencias de Henri Bergson (Tiempo y memoria) cuyas obras también leía, afirma en el Arte poética de Juan de Mairena, que "una intensa y profunda impresión del tiempo sólo nos la dan muy contados poetas". E insistiendo en que es precisamente su tiempo vital lo que el vate quiere eternizar, añade: "El poeta pretende, en efecto, que su obra trascienda de los momentos psíquicos en que es producida". Mas no se trata solamente -según Reyes- de que el poeta sepa expresar en su tiempo presente una emoción cuyas ondas espirituales hayan de vibrar y dar su perfume todavía en el futuro, sino de que el poeta exprese la experiencia vital, madurada ya, como sentimiento puro, en el recuerdo. Por su parte, Gabriel Miró lo expresa de este modo: "Hay episodios y zonas de nuestra vida que no se ven del todo hasta que los revivimos y contemplamos por el recuerdo; el recuerdo les aplica la plenitud de la conciencia; como hay emociones que no lo son del todo hasta que no reciben la fuerza lírica de la palabra plena y exacta". ${ }^{65}$

Ramón del Valle-Inclán escribió: "Toda la vida pasada era como el verso lejano que revive su evocación musical al encontrar otro verso que le guarda consonancia, y sin perder el primer significado entra a completar un significado más profundo". ${ }^{66} \mathrm{Y}$ añade: "En nuestras creaciones

${ }^{65}$ Gabriel Miró, Obras completas, 1943, Madrid, Biblioteca Nueva, p. 614.

${ }^{66}$ Ramón del Valle-Inclán, La lámpara maravillosa (Ejercicios espirituales), 1948, Madrid, Espasa Calpe, Col. Austral, núm. 8119, p. 35. 
bellas y mortales, las imágenes del mundo nunca están como los ojos las aprenden, sino como adecuaciones del recuerdo [...] El recuerdo es la alquimia que depura todas las imágenes. [...] El encanto del tiempo pasado está en la quietud con que se representa en el recuerdo". ${ }^{67}$

\section{"Teoría prosaica" o el popularismo artístico de Reyes}

“Teoría prosaica" (1931), del mismo año que "Cacería divina", nos da un buen ejemplo contrastante de la versatilidad (no veleidad) poética de Reyes. Es un poema tríptico en versos de arte menor: octosílabos y hexasílabos o pentasílabos agudos con rima consonante sin orden fijo. En él, nuestro poeta explaya su doctrina sobre los diversos elementos que pueden integrar un poema. En la primera parte de la composición traza la imagen en que se apoya una tácita comparación; con el simple recuerdo de una costumbre campesina común a México y a la Argentina, la manera de comer el cabrito al aire libre, arrancando con una estaca el pellejo, o "en la misma res mordiendo / cortando con el facón”, parece decirnos Reyes que en la vida no todo ha de ser melindres y cuidados:

¡Hasta la gente del campo nos da la lección!

Alguna vez hay que andar

sin cuchillo y tenedor,

pegado a la humilde vida

como Diógenes al charco

y como cualquier peón".

Los estudios de Reyes sobre lo popular-artístico en Góngora nos indican que no se trata aquí de un proletarismo poético, ni de un "rebajamiento" de la poesía, sino de un esfuerzo por humanizarla, acercándola un poco más a la realidad de la que el creacionismo y otras escuelas la habían ido despojando. "Conviene - escribiría Reyes años más tardeque Anteo toque otra vez, de tiempo en tiempo, la humilde tierra que lo ha criado. Conviene que la mensajera de los dioses obedezca y cumpla

${ }^{67}$ Ibid., p. 99-100. 
JOSÉ BARBA MARTÍN

su mandato, que es viajar siempre por el mundo pisando sobre el corazón de los mortales". ${ }^{68}$

En otras ocasiones repetirá: “Quien sólo canta en ‘do de pecho’ no sabe cantar" y "quien sólo trata en versos para las cosas sublimes no vive la verdadera vida de la poesía y las letras, sino que las lleva postizas como adorno para las fiestas" ${ }^{69} \mathrm{O}$ : "si he de decir todo lo que pienso, el que no sabe jugar con las letras me parece un 'arribista' del alfabeto, ya que no un analfabeto". ${ }^{70}$ Recordemos que, ya en un poema de su primera juventud (“Oración pastoral”, de 1906), había exclamado: “¡Amo la vida por la vida!"

Parecería -sugiere Roberto Fernández Retamar-que en un momento en que se repetía hasta la saciedad el término evasión, Reyes, por lo demás siguiendo una línea muy española, (pensamos en el Arcipreste de Hita o en Cervantes, en Goya o en Picasso), hubiera querido meterse en las cosas, irles al encuentro, aunque fueran los hechos de menos atrayente eternidad. $\mathrm{O}$ acaso porque, impedida de modo creciente la comunicación, le fuera necesario restablecerla por los más familiares medios. ${ }^{71}$

Sólo cuatro años antes de la fecha de "Arte prosaica", Francisco Ichaso, en una conferencia sobre Góngora y la nueva poesía, hacía notar:

Hasta tal punto ha atormentado a los artistas de la palabra esa depreciación de la materia con que manipulan, que algunos poetas, como el español Gerardo Diego, han llegado a insinuar la idea de instituir un lenguaje poético, a modo de clave cifrada cuya inteligencia sólo sería posible a una comunidad de iniciados, especie de francmasonería literaria, de carácter cerrado y exclusivista. ${ }^{72}$

Son los años en que algunos creadores líricos (Rafael Alberti, Guillermo de Torre, Jorge Guillén, Gerardo Diego) se esfuerzan por hacer del

68 "Páginas adicionales" a La experiencia literaria y a Tres puntos de exegética literaria, Obras completas de A. R., op. cit., vol. XIV, p. 381.

${ }^{69}$ Citado por Enrique González Casanova en su artículo sobre A. Reyes, Páginas sobre Alfonso Reyes, 1958, México, Universidad de Nuevo León, vol. II, p. 215.

${ }^{70}$ Ancorajes, 1961, México, Tezontle, p. 114.

71 "En torno a las ideas poéticas de Alfonso Reyes", Revista Orígenes, La Habana, 1953, Año X, No. 34, p. 73.

${ }^{72}$ Revista Avance, La Habana, 1927, p. 32. 
poema "una creación pura, peculiarísma, aislada de todo factor coincidente con la realidad", ansiosos, acuciados “por la necesidad de injertar en el poema la mayor suma de elementos poéticos y de factores de creación personal, exonerándolo de todo residuo prosaico, de todo ingrediente líricamente inútil, que cuando se mantienen en la cristalización poemática es por cobardía o inhabilidad del poeta". ${ }^{73}$ Pues bien, precisamente entonces, Reyes se ríe de aquellos que:

$$
\begin{aligned}
& \text { aunque aflojan las sujetas } \\
& \text { cuerdas de la preceptiva, } \\
& \text { huyen de la historia viva, } \\
& \text { de nada quieren hablar } \\
& \text { sino sólo frecuentar } \\
& \text { la vaguedad pura. }
\end{aligned}
$$

Y declara con cierto desenfado: "Yo prefiero promiscuar en literatura." Podemos observar, en efecto, que tanto en los temas como en los metros que usa, Alfonso Reyes se balancea entre lo muy quintaesenciado, por ejemplo: “Arte poética", "Apenas", "Silencio”, y lo más comúnmente humano: recuerdos de infancia entre rifles y caballos: "Infancia", "Los caballos"; o de viajes: "Copacabana"; o versos de ocasión, cuya composición justifica en su prólogo a Cortesía (1912-1925), recordando a Góngora, a Sor Juana, a Mallarmé, que dibujaba estrofas en los huevos de Pascua y escribía en versos las direcciones de sus cartas, y a Rubén Darío y sus poesías de cumplido social. "Hoy se ha perdido -lamenta Reyes- la buena costumbre, tan conveniente a la higiene mental, de tomar en serio - o, mejor, en broma- los versos sociales, de álbum, de cortesía..." También hay humor en la poesía de Reyes-cabe decir de paso- un humor discretísimo e intelectual, aunque caprichoso a veces por lo anacrónico o irreal del tema, o de los personajes a quienes se refiere, como cuando en su "Llanto de Briseida", de su Homero en Cuernavaca, (1949-1951), hace quejarse a la cautiva ante el recuerdo de su confidente Patroclo, muerto ya, diciendo: "para mi bien, más conve-

${ }^{73} I b i d .$, p. 38. 
niente / que mover tanto ruido y alharaca / es que Aquiles hiciera lo decente / casándose conmigo en Cuernavaca". ${ }^{74}$

Con este espíritu de hacer abarcar a la poesía toda la realidad de la vida en sus diversos aspectos y sentimientos, Reyes continúa su "Teoría prosaica": "No todo ha de ser igual / al sistema decimal: / mido a veces con almud / y a veces con cuarterón." Ramón Menéndez Pidal dirá en Los españoles en la literatura: "la belleza no se realiza conforme a ningún canon rígido, inmutable y único". 75 "Ahora bien -se preguntaba Francisco Ichaso en la conferencia citada-, ¿cuáles son los elementos intrínsecos del poema y cuáles los accesorios? ¿Cuáles los que deben permanecer y cuáles los que deben rechazarse?" 76 La tercera parte del tríptico de "Arte prosaica" responde describiendo simbólicamente esos elementos que deben entrar en el crisol del poema para darle consistencia y timbre de humanidad:
Algo de ganga en el oro, algo de tierra sorbida con la sabia vegetal; $[\ldots]$
La voz, perdida entre el coro; cera en la miel del panal y el habla vulgar fundida con el metal del habla más escogida. ${ }^{77}$

En el poema había dicho Reyes que él sabe mezclar el "romance paladino" con el refinamiento de Góngora y Mallarmé. Es la simbiosis de lo popular y de lo artístico, de lo basto y de lo refinado, una de las características que colocan la poesía de Reyes en la clara trayectoria tradicional de la expresión hispánica. Muchos recordamos la famosa conferencia de Dámaso Alonso sobre la "Escila y Caribdis de la lite-

\footnotetext{
${ }^{74}$ Obras completas de A. R., op. cit., vol. X, p. 412.

${ }^{75}$ 1960, Bs. As., Col. Austral, núm. 1271, p. 145.

${ }^{76}$ Op. cit., p. 39.

${ }^{77}$ Obras completas de A. R., op. cit., vol. X, p. 240.
} 
ratura española" (1926) ${ }^{78}$ en la que, frente a la tendencia de "selección, antirrealismo, universalismo" contrapone o asocia la vena, española también, del "popularismo, realismo, localismo". Coetáneo de Dámaso Alonso y de nuestro exquisito poeta premio Nobel Juan Ramón, es el jesuita Arturo Cayuela, cuya inolvidable obra sobre las "Humanidades Clásicas" dedica también importantes consideraciones sobre el equilibrio de estos valores literarios y humanos. ${ }^{79}$

Tanto Dámaso Alonso como Alfonso Reyes estaban bajo la influencia directa de Ramón Menéndez Pidal y éste, indirectamente, de la del polígrafo cántabro Marcelino Menéndez y Pelayo, y más, como en salto retrogresivo, de la del gran filológo decimonónico catalán Manuel Milá y Fontanals. Todos comulgan de una actitud de valoración asociativa, no disyuntiva, que trata de evitar el divorcio entre la literatura erudita y la popular y nacional, típico del siglo XVII, y cuya reconciliación sólo se llevaría a cabo, durante el romanticismo, en la filología, en los diversos géneros de poesía y narrativa, y por toda Europa a través del movimiento musical, salvador de muchos valores del folklore. ${ }^{80}$

Ya en su Introducción a la Historia general de las literaturas hispánicas ${ }^{81}$ más tarde titulada como ensayo independiente, Los españoles en la literatura, Ramón Menéndez Pidal trata de manera amplia el tema. En esa obra nos dice Menéndez Pidal que el realismo español (digamos 'hispánico'), "no consiste en ninguna preocupación de verismo inerte, en ninguna sobreestimación del pormenor insignificativo, sino en concebir la idealidad poética muy cerca de la realidad". ${ }^{82}$ Y presenta "el arte de las mayorías como predominante no sólo en volumen, sino en significación", dentro de la literatura hispánica. Arte mayoritario -dice- en

${ }^{78}$ Publicada en Cruz y raya, Madrid, 15 de octubre de 1933.

${ }^{79}$ Humanidades Clásicas, 1940, Santander, Aldus, S.A.

${ }^{80}$ Acerca de la intervención romántica y de su relación con lo popular y su canon e, incluso, acerca de la precedencia en el tratamiento de estos temas por parte de Juan Menéndez Pidal sobre el propio don Ramón, podría consultarse a Luis Díaz G. Viana, "Los guardianes de la tradición: el problema de la 'autenticidad' en la recopilación de cantos populares", Revista Transcultural de Música, número 6, 2002. Al tema del folklore Alfonso Reyes dedicó dos ensayos: "Marysias o del tema popular", recogido en "La experiencia literaria", y "Marysias o del folklore literario", recogido en "Páginas adicionales", ambos en Obras completas..., op. cit., vol. XIV.

${ }^{81}$ Dirigida por Guillermo Díaz-Plaja, 1949, Barcelona. También en la Colección Austral de Espasa-Calpe (Buenos Aires, 1960).

${ }^{82}$ Los españoles en la literatura, 1960, Buenos Aires, Espasa Calpe, p. 86. 
JOSÉ BARBA MARTÍN

el que "entra todo aquello por lo que la literatura española de los siglos pasados es generalmente conocida, todo aquello que abrió alguna huella en la literatura de otros pueblos". ${ }^{33}$ Y Juan Ramón Jiménez se pregunta: "La gran poesía ¿no es, no será siempre la que funde lo popular con lo aristocrático, en una suma de naturaleza y conciencia?"84

Pero, ¿qué entiende Alfonso Reyes por 'popular'? Responde: “por popular no entiendo desaseado y feo. Hay una limpieza y un despojo en lo popular que pueden ser ejemplares de toda elegancia" ${ }^{85}$ En el poeta Góngora mira con agrado su "modo de ser popular, sensibilidad popular, gusto natural por las cosas de que gusta el pueblo, manera espontánea de andar entre la gente humilde y no sentirse aparte de ella. [...] Y, hasta en los momentos más descuidados de su poesía, su poquillo de ramplonería consciente..." ${ }^{86}$ No se trata, pues, de una "proletarización" de la poesía, como la llamé antes. Reyes mismo, en el ensayo sobre Góngora ya mencionado, nos previene contra las confusiones a que se presta el vocabulario político trasladado al campo de la literatura. Así, aclarando el tema que aquí nos ocupa, dice:

Los escritores que sólo de muy mala gana me resuelvo a llamar aristocráticos no tienen por qué ser aristócratas en el sentido político de la palabra. Al contrario, es de constante experiencia que el arte erudito se comunica con el pueblo, lo busca, lo solicita, se inspira en él como Goethe partía de las pequeñas comedias de "títeres" para llegar a la profunda concepción de su Fausto.

Y, luego, en un involuntario autorretrato, añade:

Grandes poetas, que son a la vez humanistas consumados, han dejado, por una parte, poemas de excelso refinamiento, $y$, por otra, se han inclinado con amorosa comprensión hacia el folklore, buscando en la inventiva popular raíces de inspiración y asunto de gustoso estudio.

${ }^{83}$ Ibid., p. 124.

${ }^{84}$ Citado por R. Menéndez Pidal, op. cit., p. 128.

${ }^{85}$ Ibid., p. 126.

86 "Lo popular en Góngora", en Cuestiones estéticas, Obras completas de A. R., op. cit., vol. VII, p. 203. 
Como prueba de ello en la poesía de Reyes, citaré el siguiente ejemplo. En "Glosa de mi tierra" (1917), que pertenece al período de 1913-1924, Reyes ha tomado una bella letrilla popular de las bien conocidas "Mañanitas", canción de alborada con que en México despertamos a una mujer o a un ser querido el día de su "santo" o de su cumpleaños, y ha engarzado cada uno de los cuatro versos octosílabos al final de sendas décimas o espinelas. Éstas, siendo de origen cortesano, se difundieron mucho en los pueblos campesinos de América. ${ }^{87}$ La letrilla popular canta así:
Amapolita dorada
de los valles de Tepic:
si no estás enamorada,
enamórate de mí. ${ }^{88}$

Reyes introdujo una ligera variante en el segundo verso:
Amapolita dorada
del valle donde nací:
si no estás enamorada, enamórate de mí. ${ }^{89}$

No haríamos bien en omitir la transcripción, por lo menos de la primera décima, en cuya lectura, por instantes, tenemos la ilusión de estar disfrutando al mismo Góngora:

Aduerma el rojo clavel

o el blanco jazmín las sienes;

que el cardo es sólo desdenes,

y sólo furia el laurel.

Dé el monacillo su miel

y la naranja rugada

y la sedienta granada

${ }^{87}$ Ibid., p. 202.

${ }^{88}$ Ibid., p. 199.

${ }^{89} \mathrm{Ibid}$., p. 200. 


$$
\begin{aligned}
& \text { zumo y sangre -oro y rubí-; } \\
& \text { que yo te prefiero a ti, } \\
& \text { amapolita dorada. }
\end{aligned}
$$

"Y toda la literatura de nuestra lengua-añadirá Reyes en su ensayo, continuando de cerca las ideas de Ramón Menéndez Pidal- está llena de confortantes ejemplos parecidos, porque es característico de la cultura española el traer consigo un acarreo de popularismo más abundante en general que el que han logrado incorporar otras culturas occidentales. Quien no se penetre de esta inspiración de popularismo no entenderá nunca la historia de la literatura española." Pero esa trasvasación, ese acrisolamiento entre lo popular y lo culto, nos advierte Reyes, "no lo consigue todo el que quiere. No todo el que lo desea logra subir a temperatura artística el metal del pueblo. Hace falta una electricidad especial, un especial temple poético. Así, no sólo es verdad que muchas veces el poeta erudito se acerca al pueblo, sino que además, hay notas populares a las que sólo puede dar pasaporte artístico el poeta erudito". ${ }^{90}$

Enrique Anderson Imbert reconoció a Reyes como uno de esos vates cuando dijo, en uno de sus seminarios de Cambridge: "Alfonso Reyes pertenece a esa clase intelectual americana que acertó, de una vez por todas, en el problema de la expresión: crear el propio destino desde el fondo de la tradición."

$$
* * *
$$

Cerramos estos apuntes con una breve nota para quienes no se hubieren adentrado antes en la obra de Alfonso Reyes: con la lectura sola de los subtítulos e índices de sus obras, a la primera podría parecerles que habría sido más pertinente, para el propósito de este artículo, la consulta exhaustiva de El deslinde, esa "summa" orgánica del conocimiento literario reyiano. Pero durante la vida misma del autor, no fue cálida la acogida del público intelectual a esas cultas, concurridas y muy disciplinadas 'lecciones sobre la Ciencia de la Literatura' dictadas en el Colegio michoacano de San Nicolás, entre mayo y junio de 1940 (“¡Ah, si mi

${ }^{90}$ Ibid., p. 203. 
Deslinde estuviera redactado en alemán!" - dicen que exclamó una vez, con amarga ironía, el vate mexicano); aunque Octavio Paz, quien también fue su oyente en Morelia, recuerda con agrado esas conferencias al inicio de El arco y la lira. En esas "lecciones", Reyes quiso darnos una "investigación retrospectiva del propio itinerario, que es un imperioso reclamo de la conciencia" cuya preparación le ayudó - dice- "a poner un poco de orden en los hacecillos dispersos de una obra siempre desarticulada por una existencia de viajero". Testimoniaba un frustrado anhelo: "todos tenemos derecho - pero casi siempre nos lo estorba la vida- a procurar la unidad, la confortante unidad [...] antes de que Octubre me invada". ${ }^{91}$

Pero la savia del sentir y de la experiencia artísticos de Reyes -según muchas citas de este trabajo habrán podido comprobarlo- como lírico, como crítico y como hombre de letras, se halla fluyendo más ricamente por el resto del cuerpo de su obra completa, sobre todo en los trabajos especialmente dedicados a la investigación y a la contemplación literarias: La experiencia literaria y Tres puntos de exegética literaria; en Cuestiones gongorinas, Al yunque y en Ancorajes. ${ }^{92}$ En esos estudios y meditaciones “iqué jardín del Abril, qué Aranjuez del Mayo!” nos ofrece Reyes (empleo aquí palabras que Baltasar Gracián aplica al goce que brinda una biblioteca exquisitamente formada y que nuestro poeta recordó también oportunamente). ${ }^{93}$

${ }^{91}$ En el Prólogo a El deslinde, Prolegómenos a la teoría literaria, 1944, México, El Colegio de México; Obras Completas..., op. cit., v. XV, p. 19.

${ }^{92}$ Obras completas, op. cit., v. VII, v. XIV y v. XXI, respectivamente.

93 "Apolo o de la literatura", en ibid., v. XIV, p. 98. 
CITAM Derechos Reservados.

La reproducción total o parcial de este artículo se podrá hacer si el ITAM otorga la autorización previamente por escrito. 